it may be many years before the myth completely disappears. Until then Professor Waldeyer will have repudiated his results in vain, for it will always be stated that he "proved" a somatic origin!

In his letters, as in his book, your correspondent provides excellent texts. Of course, "a single scale from the leaf or stem of a plant suffices for the reproduction of the whole organism." But the little finger of a man's hand or a bit of his skin has not this potency and there is no comparison possible between the asexual generation of plants, the sporophyte or flowering plant, and the sexual generation of animals, "the embryo" or individual. The conditions are, however, similar in the asexual generations of the two. .Just as a single scale of a flowering plant may produce the whole individual plant, so also a small bit, even a single cell, of the trophoblast may on occasion give rise to ever more and more trophoblast, and the like is true of a malignant neoplasm. In all these instances we may witness unlimited powers of growth. This is why, for example, many of our choicest and commonest flowering plants owe their origin to a single individual plant which cannot with certainty be again produced from seed. This is why the investigators of the Imperial Cancer Research Fund were able from one fragment of a mouse tumour to "grow" ever so many pounds of cancer, transplanting other little bits to new ground. This is also one reason why cancer and sarcoma cells are never embryonic or somatic.

In my first article upon cancer in THE LANCET ${ }^{2}$ there is in a footnote a rather long reference to the experimental researches of Driesch, E. B. Wilson, and others, who have followed in the footsteps of Roux. Is your correspondent aware that more recent investigators have considerably modified some of Roux's earlier results? Among his numerous observations Professor Roux has never recorded any work upon the origin and history of the germ cells of vertebrates. That he was the first to carry out certain experiments upon eggs in cleavage has no connexion with the question of the morphological continuity of germ cells or with that of the course of the life-cycle. In his former letter your correspondent had words of praise for Herbert Spencer ; in his present one he strongly condemns him along with Weismann and myself. The association of my name, even in a damnatory sense, with the honoured ones of Weismann and Spencer, two good and faithful servants of mankind, cannot be other than complimentary, and it is herewith accepted as such a compliment. "The future alone will decide the strength and stability of my "craft." I venture to believe that it may perchance weather all storms, for I know only too well what amount of hard, often midnight, work, unrequited by all else except results, it and its small cargo have cost.

Dec. 23rd, 1904.

I am, Sirs, yours faithfully,

$$
\text { J. BEARD. }
$$

*** Dr. Beard's lecture, which originated this discussion, appeared in our columns on Oct. 29th, 1904, p. 1200 . We have given now as much space to the controversy as we can aftord.-ED. L.

\section{HOSPITAL "ISOLATION."}

\section{To the Editors of THE LANCET.}

SIRS,-In your issue of Dec. 17th, 1904, p. 1737, you make the following quotation from a communication received from Dr. F. Lucas Benham of Exeter, South Australia. "In THE LANCET of June 13th, 1896, you will find a letter from me on 'Isolation and the Public Health Act,' in which I think I anticipated even Mr. Marriott in contending that the necessity for public hospitals for infectious diseases was far from being proved...... In
your issue of the following week (June 20th, 1896) Mr. Berry of Wigan wrote a letter in my support and not long after Mr. Marriott of Nottingham also entered the field on the same side." From this it would appear that I have usurped without the least acknowledgment the position of another. It happens, however, that I was in active opposition to the "isolation" craze 20 (or more) years ago and that many years before the appearance of Dr. Benham's letter (which it was my misfortune not to see) I was writing voluminousiy on the "isolation" question. Unfortunately, I have not any of these early communications in my possession but many of them were preserved by my distinguished friend Dr. $\mathrm{C}$. Bell Taylor and are still available. It must be 25 years since the "Liverpool Committee" paid me a visit and took down my evidence in re the working of the local Notification Acts, which evidence was published verbatim in a report which is still extant.

To those who remember the days when the aggregation of all sick was regarded as a mistake to be remedied by the building of cottage hospitals the advancement of so selfevident a proposition as that the aggregation of the infective sick in large permanent hospitals must be bad will not appear to justify any considerable claim to honour and glory. Let us keep in mind the fact that nobody has ever yet explained the raison d'être of the aggregation hospital. The earliest experiment injured or killed everybody concerned with it, which made Sir Thomas Watson exclaim that but for a certain fact, now known to have been a fiction, these institutions which "concentrate the poison" were little else than a public danger. Later down the stream of time a chief inspector of the Local Government Board, Dr. Thorne, after having sung the praises of the "isolation" hospital to the Royal Commissioners on vaccination, was telling these Commissioners that he had made a great mistake and that the establishment of isolation hospitals at Leicester and Warrington had been accompanied by a marked increase in the scarlet fever attack rate. Since then sanitarians have been urging the municipalities all over the kingdom to build these hospitals without once telling them the reason why, and nobody knows or ever knew the reason why. The method of procedure was brilliantly illustrated recently at Lincoln. A few years ago this city was visited by an epidemic of-something. Dr. L. W. Darra Mair, a gentleman who always approaches these investigations in a purely scientific spirit, was sent down from the Local Government Board to hold an inquiry. The inspector soon discovered that whatever it was he had to deal with it was not an epidemic of scarlet fever and that the trouble was not infectious. What happened? Lincoln forthwith broke out into an "isolation" hospital and only the other day his Grace the Bishop, surrounded by his entourage, was pouring out a libation to the gods because at last they could send the sick citizens to a place where if they had not got scarlet fever already they very soon would get it-and something else besides-and from which they would be able to return when convalescent to sow fever-and something else besides-broadcast in the interests of public health and as an object-lesson in preventive medicine. In conclusion, Sirs, I congratulate Dr. Benham on the fact that he contented himself with a letter in THE LANCET. Had he carried the thing further he might by this time have been the mauvais sujet of the public health profession. Instead of the peaceful life he is now living he would, having transgressed the sacred canons of that profession, have discovered that the way of transgressors is hard and that any stick is good enough to beat a medical reformer with. I am, Sirs, Jours faithfully,

Nottingham, Dec. 24th, $1904 . \quad$ EDWD. DEAN MarRIoTt.

\section{THE EVOLUTION OF MAN'S DIET.} To the Editors of THE LANCET.

Sins,-I am not sure that Dr. Harry Campbell's general statements with regard to the digestion of cellulose have materially altered my views, but I venture to think that he has raised some points which would tend to support my position. Dr. Campbell brings forward the fact that a certain amount of chemical solution of cellulose takes place both in anthropoids and in man, but does not show that anthropoids are any more able to digest it efficiently than man by the agencies referred to. Cellulose "is remarkable for its great resistance to the most varied chemical reagents" and the digestion referred to is practically negligible, for the chief importance of cellulose in the diet lies in its inert and mechanical properties. Then, again, he suggests that the bitter and acrid taste of the food of anthropoids renders it quite unfit for human consumption. May we not suggent that these acrid and bitter tastes are the natural excitants of the salivary and other glands which have to do with the maceration and preparation of the cellulose? Moreover, if we at times were driven by hunger to eit such bitter foods might we not acquire the taste for them? Vegetable foorts, especially fruits, very generally associate cellulose, sugars, acids, 
and acrid principles and it is scarcely right to consider the effects of any one of them when dissociated from the others. 'They naturally supplement each other. Thus while the cellulose on account of its physical nature is arrested in the mouth and disintegrated by the teeth the acids and acrid principles stimulate the flow of saliva and help to loosen the cellulose framework. Further, the acrid taste often remains in the mouth and continues to stimulate the flow of saliva even after the food has been swallowed. Then, again, the sugars stimulate the secretion of saliva, which further helps to macerate the cellulose. The mucous glands are likewise stimulated, and so the cellulose, and even any ligneous shreds which may accompany it, are coated with mucus and rendered fit for passage along the alimentary canal. Moreover, this copious secretion of saliva helps the more thoroughly to convert the starch and sugars, and the prolongation of the stage of alkaline digestion in the stomach has a certain importance in further disintegrating the cellulose.

It is not only on account of the effect on the cellulose that I would refer to the collateral benefits of bitter and acrid tastes. I would refer to them because the orthodox habit of giving young children almost nothing but soft, bland, generally alkaline food has disastrous effects that are never dreamt of. Thus, being for prolonged periods deprived of these bitter and acrid substances, when opportunity affords children very generally over-indulge in quite unripe and acrid fruits or acid drinks. If, however, the taste for bitter principles is allowed, or, better, gradually stimulated to develop, then such excesses are not indulged in. Similarly, a liberal supply of fresh ripe fruit helps to prevent the craving for, and excessive indulgence in, sugar or sweets. At first strongly acrid flavours, generally and advantageously, act as deterrants in the selection of foods but by experiment and by following the example of the parents the taste for these bitter principles becomes largely acquired. Frequent association of acrid with irritant principles, however, has naturally prevented a pronounced development of the instinct for bitter principles which, when fully developed, is somewhat antagonistic to the desire for sweets. The supply of sugar which was available for our ancestors was very limited and therefore prevented an excessive indulgence in it however strong the craving for it became. It is important to recognize this fact, not because the ruin of the teeth gives rise to many more serious troubles, nor because the injury to the teeth means ruin to the power to digest and relish some of the most luscious foods, but because it has become the fashion to belaud the dietetic value of sugar and to look upon it as an important food, while in reality it should be sparingly used and regarded rather as a condiment. What does it matter whether we can turn sugar into so many units of energy if at the same time it ruins the teeth and irritates the stomach to such an extent that healthy and vigorous digestion is lost? The use of condiments is a practical recognition of the value of bitter and acrid principles and a study of them reveals a philosophy which ought to influence our precepts with regard to the feeding of children.

It is, perhaps, impossible to estimate how far the capabilities of digesting or transmitting cellulose might be improved if the natural potentialities were allowed or stimulated to develop, instead of being suppressed and perverted. However, whether I have exaggerated our capabilities of transmitting cellulose or not, it is sufficient to find Dr. Campbell so distinctly enforcing our belief that "if physicians could be got to realise the importance of providing the jaws, teeth, and the muscular coats of the digestive tract with adequate work an untold amount of disease and suffering would be averted."

I am, Sirs, yours faithfully,

Wimpole-street, W., Dec. 24th, $1904 . \quad$ J. SIM WALLACE.

\section{"WHO'S WHO" YEAR BOOK AND THE MEDICAL PROFESSION.}

To the Editors of THE LANCET.

SIRs,-My attention has been called to a list of "leading London specialists" in the above publication for 1905 in which my name has been included. I hope it is unnecessary to say that this has been done without my knowledge or consent. My object in writing is to point out how harmful to the public as well as to the profession the information thus afforded, inperfect and generally misleading as it is, must be. Although I understand that the publication of names in this way is not legally preventable, notice of the matter in the columns of THE LANCE'T should go far towards avoiding a repetition of such a regrettable proceeding.

I am, Sirs, yours faithfully

William H. BenNeTt.

Chesterfield-street, Mayfair, W., Dec. 30th, 1904.

\section{THE CAUSATION OF SEX.}

\section{To the Editors of THE LANCET.}

SIRs,--In THE LANCET of Sept. 26th, 1891, p. 713 appeared a paper by Dr. Andrew Wilson of Fdinburgh advancing a provisional theory of sex determination, according to which the causation of sex was primarily a matter of nutrition affecting the ovum at the time of fertilisation; that is to say, an ovum fertilised pre menstrually, being stronger and more vital, tends towards the male side, while an ovum fertilised post-menstrually, having lost much of its vitality, tends towards the female side. In 1893 a further article appeared in your columns ${ }^{1}$ giving illustrative cases in support of the theory.

Now, without having any bias in favour of this or any other theory it appeared to me that it would be a matter of interest to put it to the test of practice under conditions which absolutely precluded any source of error. This has been done with the following results:-

X., aged 28 years, married in 1897 ; previous menstrual history normal; no conception permitted for one year, during which menstruation was perfectly regular. Child I.: In 1898 a girl was desired. The last menstrual period ended on Feb. 6th, 1898; impregnation took place between Feb. 8th and 16th-i.e., was post-menstrual ; confinement expected Nov. 13th; actual date of birth Nov. 14th; result a girl; subsequent menstruation regular. Child II. : A boy desired; last menstrual period ended Oct. 3rd, 1900; impregnation took place between Sept. 24th and Oct. 2nd-i.e., premenstrually ; confinement expected July 10th, 1901; actual date of birth June 28th, 1901; result a boy; subsequent menstruation regular. Child III. : A girl desired; last menstrual period ended Feb. 27th. 1904; impregnation postmenstrual, between March 1st and 11th, 1904 ; confinement expected Dec. 4th, 1904 ; actual date of birth Dec. 2nd; result a girl.

In these three instances the result occurred as desired; conception was impossible at any other times than those stated, and in each case the prediction was communicated beforehand to a medical friend. No other children were born and no miscarriages occurred. The theory in question involves the assumption of a relationship between ovulation and menstruation which has, so far as I am aware, not yet been proved. The facts, so far as they go, lend support to the theory though the cases are, of course, too few to be of much value. To obtain precise and definite data on this question is a matter of considerable difficulty, and a few cases in which the facts are certain are worth many in which there may be some element of uncertainty. Hence my reason for recording them. If the theory be correct that sex is already determined in the ovum before impregnation takes place these instances of pre-determination must be regarded as pure coincidences; coincidences, however, which under the conditions of the experiment can only be characterised as striking. For obvious reasons I withhold my name but inclose my card and shall be happy to communicate through you, Sirs, with anyone desiring further information.

$$
\text { I am, Sirs, yours faithfully, }
$$

\section{THE L.S.A. QUALIFICATION AND MEDICAL} APPOINTMENTS.

To the Editors of THE LANCET.

SIRS, --I am a member of a board which frequently has the duty of appointing a house surgeon and among the applicants we of ten have men holding the double qualification of the L.S.A. Lond. Almost invariably either a lay or medical member of the board will raise some objection to the L.S.A., mentioning that he thinks it an inferior qualification to the Conjoint Board of England, Scotland, and Ireland. Having employed men holding all the above 